\title{
RELATO DE EXPERIÊNCIA SOBRE A PRODUÇÃO DE VÍDEOS PARA CONJUGAÇÃO ENTRE TEORIA E PRÁTICA NO ENSINO TÉCNICO EM INFORMÁTICA
}

\author{
EXPERIENCE REPORT ON THE PRODUCTION OF VIDEOS FOR \\ CONJUGATION BETWEEN THEORY AND PRACTICE IN TECHNICAL \\ TEACHING IN DATA PROCESSING
}

\author{
Diego de Souza Muguet \\ Professor de Programação e Banco de Dados na Fundação de Apoio à Escola Técnica (FAETEC) / \\ Engenheiro de Aplicativos em Órama Investimentos \\ https://orcid.org/0000-0002-9339-690 \\ Sebastião Coelho de Melo \\ Professor de Informática na Fundação de Apoio à Escola Técnica (FAETEC) / Tecnólogo em \\ Processamento de Dados \\ https://orcid.org/0000-0001-5826-9529 \\ Luciane Medeiros de Souza Conrado \\ Pesquisadora e Professora no Centro Universitário Unicarioca / Cientista Social (UFRJ) / Mestre em Ciência \\ da Arte (UFF) / Doutora em Letras (Linguística - Estudos das Linguagens - UFF) \\ https://orcid.org/0000-0002-1487-5401 \\ Ana Paula Legey de Siqueira \\ Professora no Centro Universitário Unicarioca / Pesquisadora Colaboradora na área de Divulgação \\ Científica no Instituto de Engenharia Nuclear / Doutora em Divulgação Científica (IEN/CNEN) \\ https://orcid.org/0000-0002-9056-9844

\section{Leonardo Trotta} \\ Professor no Centro Universitário Unicarioca / Secretaria Educação (SEEDUC) \\ https://orcid.org/0000-0001-7411-9352 \\ Data de submissão: 15/03/2020 \\ Data de aprovação: 30/05/2020
}

\section{RESUMO}

O presente artigo é um relato de experiência científica sobre a produção de vídeos na disciplina cujo nome é Banco de Dados no curso técnico de informática na unidade da Fundação de Apoio à Escola Técnica (FAETEC) - Maria Mercedes Mendes Teixeira. O objetivo do trabalho foi analisar os resultados obtidos nas avaliações práticas do segundo bimestre dos estudantes que assistiram a todas as videoaulas disponibilizadas em plataforma on-line (Google Sala de Aula). Participaram do trabalho 14 estudantes do segundo módulo (de um total de três) do curso técnico em informática, todos maiores e de ambos os sexos. Baseado no baixo desempenho da turma na avaliação do primeiro bimestre, que sempre é prática, percebeu-se a dificuldade na aplicação de soluções envolvendo álgebra relacional aplicada ao banco de dados MySQL em situações ou problemas do mundo real inerentes ao armazenamento, controle e manutenção de dados. Com base em estudos que indicam o vídeo como uma mídia de forte engajamento na sociedade, todo conteúdo do segundo bimestre foi produzido nesse formato e disponibilizado para utilização dos estudantes durante todo ciclo bimestral. A experiência permitiu a reflexão de que os vídeos podem ter papel de protagonismo no desempenho do estudante em relação às atividades práticas propostas no Curso Técnico em Informática, 
em que a demanda pelo exercício da função requer intenso treino, crítica e vivência de situações próximas à realidade do setor produtivo.

Palavras-chave: Produção de Vídeos. Google Sala de Aula. Curso técnico em informática.

\section{ABSTRACT}

This article is a report of scientific experience on the production of videos in the discipline whose name is Database in the technical course of computer science at the unit Fundação de Apoio à Escola Técnica (FAETEC) - Maria Mercedes Mendes Teixeira. The objective of the work was to analyze the results obtained in the practical evaluations of the second two months of the students who watched all the video classes available on online platform (Google Classroom). 14 students from the second module (out of a total of three) took part in the technical course in computer science, all of whom were older and of both sexes. Based on the low performance of the class in the evaluation of the first two months, which is always practical, the difficulty in applying solutions involving relational algebra applied to the MySQL database in real world or problems inherent to the storage, control and maintenance of data was noticed. Dice. Based on studies that indicate video as a medium of strong engagement in society, all content from the second quarter was produced in this format and made available for use by students throughout the two-month cycle. The experience allowed the reflection that the videos can play a leading role in the student's performance in relation to the practical activities proposed in the Technical Course in Informatics, in which the demand for the exercise of the function requires intense training, criticism and experiencing situations close to reality the productive sector.

Keywords: Video production. Google Classroom. Technical course in informatics.

\section{INTRODUÇÃO}

Vive-se numa realidade em que as tecnologias fazem parte do dia a dia do indivíduo na sociedade. As mais variadas tecnologias da informação e comunicação (TIC) vêm aumentando e impactando praticamente todas as esferas de atuação do indivíduo, o que inclui a escola. Novas exigências surgem e com a realidade da Indústria 4.0, novas oportunidades aparecem e a capacitação profissional se torna primordial.

Segundo Zandvliet (2012 apud SANTOS; ALMEIDA; ZANOTELO, 2018) a crescente inserção das TICs nos sistemas educacionais se deve a inevitáveis pressões de naturezas tecnológicas, sociais, políticas e econômicas, refletindo no aumento da quantidade de aparatos tecnológicos adquiridos para as escolas e pela diversidade de possibilidades de seus usos para fins didáticos, que têm sido objeto de debates e pesquisas.

De acordo com Serafim e Sousa (2011) a escola, na atualidade, advém de uma era industrial, sua estrutura foi estabelecida de modo a preparar as pessoas para viver e trabalhar na sociedade que agora está sendo convocada a aprender, tendo em vista as novas exigências de formação de indivíduos, profissionais e cidadãos, demandas que são extremamente distintas das que eram necessárias na era industrial. Assim, a escola acaba por ter que se "se reinventar" para sobreviver como instituição educacional. Os professores são levados a conscientizarem-se da necessidade de apropriarem-se de saberes advindos com a presença das tecnologias digitais da informação e da comunicação para que estes possam ser sistematizadas em sua prática pedagógica (SERAFIM; SOUSA, 2011, p. 20).

Hoje, já não cabe o predomínio da comunicação vertical, em que o professor é o detentor do saber absoluto. Faz-se necessário que haja uma interação maior entre professor e aluno, em que o último possa discutir suas ideias, suas experiências. 
Diante da nova realidade vivenciada pelo Sistema Educacional, o presente trabalho trata-se de um relato científico sobre a utilização dos vídeos aplicados ao curso técnico em informática como forma de mitigar o abismo que existe entre teoria e prática, objetivando suprir as demandas do mundo moderno onde o profissional deve ser dinâmico, criativo, eficiente e eficaz em suas soluções.

Neste sentido, estudantes e professores quanto mais engajados no mundo digital, suas tecnologias e ferramentas, maiores serão as possibilidades de um processo de ensino-aprendizagem significativo e de qualidade.

\section{REFERENCIAL TEÓRICO}

\subsection{Os desafios dos jovens no mercado de trabalho}

Segundo dados do IBGE (2019), a taxa histórica do desemprego entre os jovens (18 a 24 anos) é maior que no restante da população. O Estado do Rio de Janeiro é o terceiro no Brasil, que mais abriga jovens desempregados em todo país (IBGE, 2019) tornando a situação deles muito difícil em relação à sua entrada e absorção pelo setor produtivo, ou seja, o mercado de trabalho.

Ainda segundo o IBGE (2019), os jovens com menor qualificação são os que mais sofrem para entrar no mercado de trabalho, pois a população com ensino técnico, graduação e pós-graduação está representada no grupo com as menores taxas de desemprego.

Portanto, é perfeitamente cabível inferir que os jovens com maior qualificação possam se adequar em vagas que ofereçam menores salários devido ao momento notório de recessão econômica, tornando o acesso dos jovens sem qualificação ao mercado de trabalho ainda mais complexo.

"A digitalização das indústrias e seus sistemas de produção inteligentes trazem maior produtividade e competitividade, novas soluções tecnológicas surgem impulsionando o consumo cada vez maior de produtos conectados." (FIRJAN; SENAI; FINEP, 2019, p. 21).

Vislumbra-se um cenário de oportunidades para mão de obra qualificada na área tecnológica, com amplo destaque para as subáreas da informática que requerem um poder cada vez maior de inovação e soluções criativas para atender às demandas dos sistemas de produção inteligentes. Sendo que as barreiras que dificultam a adoção dessas tecnologias estão associadas à falta de mão de obra qualificada (FIRJAN; SENAI; FINEP, 2019).

A ausência de profissionais de tecnologia qualificados para o preenchimento de determinadas vagas passa por dois cenários: I) a baixa disponibilidade de pessoal com a formação técnica; II) os profissionais possuem a formação técnica, mas não conseguem desempenhar adequadamente as funções práticas propostas pela indústria empregadora. (FIRJAN; SENAI; FINEP, 2019, p. 22).

Assim, percebe-se que a conjugação entre teoria e prática é um desafio para os educadores de nível técnico, pois o estudante precisa vivenciar situações próximas à realidade para que tenha condições de absorção no mercado de trabalho. Urge trabalhar com clareza teoria e prática, para que de fato, o estudante tenha a consolidação do conhecimento.

Conforme Santos (2010, p. 5) “[...] teoria e prática mantêm uma relação de unidade na diversidade, formam uma relação intrínseca, sendo o âmbito da primeira 0 da possibilidade e o da segunda o da efetividade". 
Teoria e prática se movimentam de forma distinta e específica a cada conjunto, porém, em unidade, conforme afirma Santos (2010, p. 27) ao dizer que:

A teoria se distingue da prática, é ato do pensamento, o qual, todavia, dirige-se para um objeto - produto da prática -, ou seja, a teoria almeja o conhecimento da constituição do concreto, entretanto, esse concreto tem sua gênese na prática, é nela que se expressam as determinações do objeto. Dessa forma, teoria e prática se distinguem ao mesmo tempo em que estabelecem uma relação de unidade.

Portanto, é possível perceber que teoria é o conjunto de fatores determinados pelo pensamento a partir dos mais diversos movimentos cognitivos, ao qual projeta-se um objeto, problema ou situação prática para aplicação de fundamentos essenciais concomitantemente às experiências intrínsecas a cada indivíduo.

E a prática é a materialização de ações concretas efetivamente aplicadas em um problema, situação ou fator determinante do mundo real com procedimentos e métodos bem definidos.

Percebe-se que a prática não é um receituário de aplicação da teoria, pois o mundo real envolve variáveis que se modificam a todo momento, exigindo assim, que o indivíduo esteja atualizando-se e busque cada vez mais capacitar-se.

A qualificação profissional além de aumentar a empregabilidade, também colabora com o aumento do valor do profissional no mercado de trabalho.

\subsection{A Utilização de Multimídias na Aprendizagem}

As Tecnologias multimídia cada vez mais vem sendo utilizadas em salas de aula e tem evidenciado sua importância no campo educacional. Mas se faz necessário que os docentes sejam capacitados para que façam uso corretamente das ferramentas tecnológicas (Figura 1).

Serafim e Souza (2011) revelam que o preparo dos docentes brasileiros para a utilização de mídias e objetos digitais como materiais didático-pedagógicos ainda é insipiente.

Para que haja um bom aproveitamento das potencialidades do vídeo, é imprescindível que os professores tenham uma formação específica para a utilização do meio. Não haverá professores formados para o emprego do vídeo e demais audiovisuais se não houve professores formados mediante o emprego do vídeo e dos demais audiovisuais (FERRÉS, 1996, p. 11 apud CARVALHO, 2017).

Para utilização de recursos multimídia se faz necessário conhecer as características das tecnologias para que se possa adequar as combinações de informação visual e auditiva às mensagens que se deseja transmitir e, dotado daquele conhecimento, planejar, antes de desenvolver e produzir uma aplicação multimídia interativa (VIEIRA; SOUZA, 2016).

Por meio da multimídia podem ser criados diversos recursos pedagógicos, como por exemplo, os objetos de aprendizagem (OA) que são recursos digitais reutilizáveis e apropriados ao uso educacional. "Pode ser qualquer material digital, como textos, animação, vídeos, imagens, aplicações, páginas web de forma isolada ou em combinação, com fins educacionais" (VIEIRA; SOUZA, 2016, p.125).

São recursos considerados autônomos, que podem ser utilizados tanto como módulos de um determinado conteúdo, como um conteúdo completo, sendo também destinados a ambientes de aprendizagem, que pode ser em sala de aula, na modalidade presencial, mas também na modalidade semipresencial e a distância. 


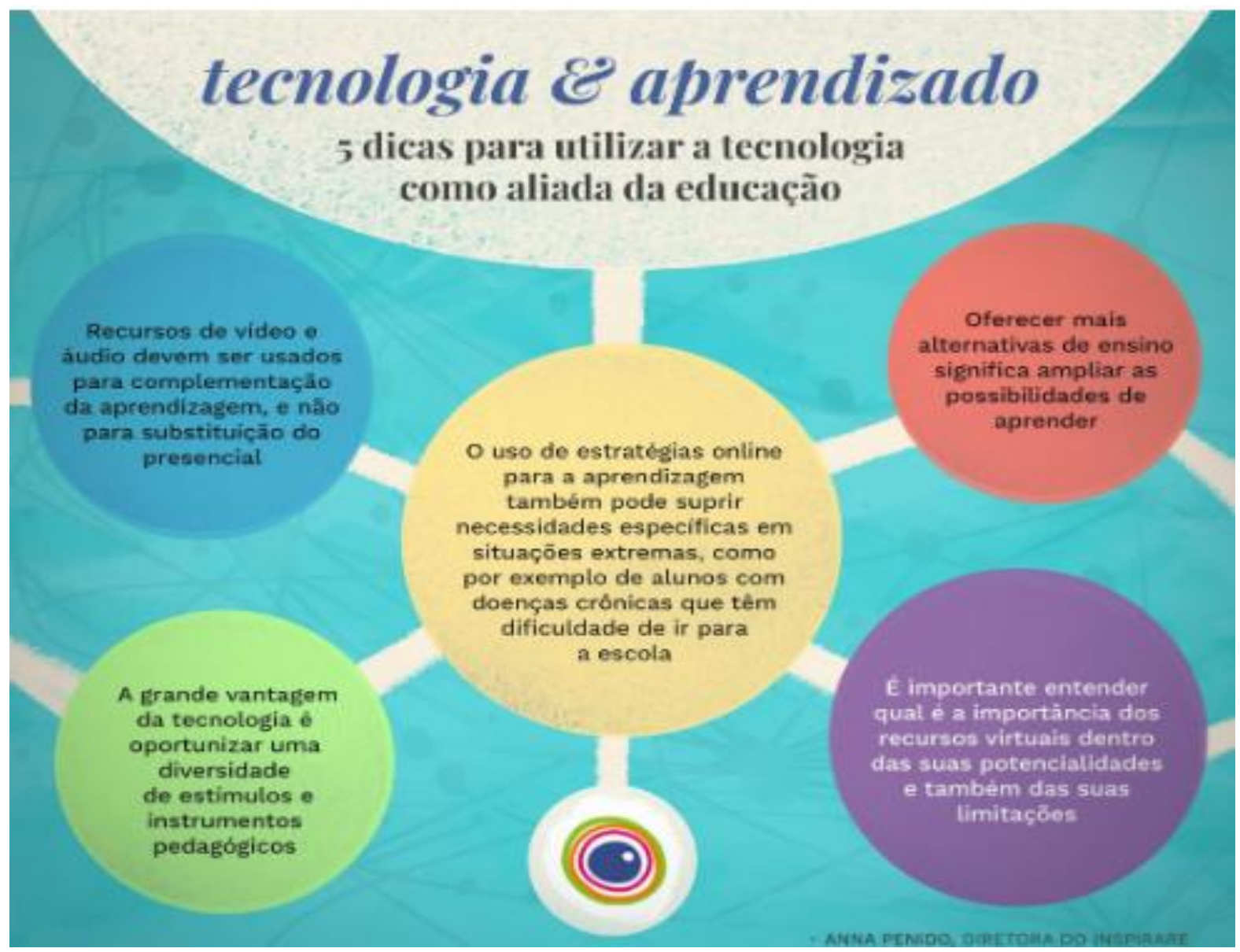

Fonte: LUNETAS (2018).

\subsubsection{Vídeo no contexto educacional}

O uso do vídeo pelas escolas como ferramenta motivacional não é recente. Diante dos desafios na educação para que teoria e prática tenham adequada conjugação na aprendizagem dos futuros técnicos e profissionais de informática, o vídeo surge como uma ferramenta de significativo potencial para o sucesso da aprendizagem necessária à prática profissional devido ao seu elevado potencial de engajamento, conforme afirma Dallacosta et al. (2004) ao dizer que:

A utilização de vídeos na educação facilita a aproximação entre a realidade escolar e os interesses dos alunos. Vivemos um tempo em que as imagens assumem um papel de lazer com o qual a escola não pode competir. Porém, se ao contrário os professores utilizarem-se deste recurso junto a uma proposta de currículo integrado, parece-nos que a escola se tornará mais próxima da realidade dos alunos e consequentemente mais interessante para estes. (DALLACOSTA et al., 2004, p. 420).

Serafim e Souza (2011) esclarecem que as potencialidades do vídeo permitem uma "interatividade funcional", pois:

O vídeo é sensorial, visual, linguagem falada, linguagem musical e escrita. Linguagens que interagem superpostas, interligadas, somadas, não separadas. Daí a sua força. Somos atingidos por todos os sentidos e de todas as maneiras. O vídeo nos seduz, informa, entretém, projeta em outras realidades (no imaginário), em outros tempos e espaços (MORAN, 1995 apud SERAFIM; SOUZA, 2011, p. 30). 
Carvalho (2017) relata que o recurso audiovisual pode ser uma importante ferramenta, pois proporciona o aprendizado por meio do lúdico o que pode prover um melhor aprendizado, contribuindo para o desenvolvimento intelectual do aluno, além da compreensão e assimilação dos conteúdos, de modo a motivá-lo e aproximá-lo da realidade.

A vantagem dos vídeos é que os mesmos podem ser disponibilizados em "nuvem", em grandes servidores de streaming como, por exemplo, o YouTube, para que os usuários dessas mídias possam adquirir os conteúdos sob demanda.

Umas das grandes vantagens do uso do vídeo digital é que ele poderá ser disponibilizado na Web. Os vídeos educacionais que em geral são disponibilizados em uma videoteca ou uma biblioteca ficariam acessíveis em um repositório de vídeos educacionais fazendo com que se tornem acessíveis por um grande número de pessoas (DALLACOSTA et al., 2004, p. 422).

\section{METODOLOGIA}

O objeto de estudo foi aplicado na disciplina de Banco de Dados II (SQL) em uma turma de segundo módulo no Curso Técnico em Informática da FAETEC, todos maiores e de ambos os sexos, totalizando 14 (catorze) estudantes. A disciplina citada requer número elevado de situações práticas, pois compreende a manipulação de dados em um banco de dados, situação que apresenta um elevado número de utilização, desde os negócios mais básicos até as grandes corporações. Sendo, portanto, os conhecimentos adquiridos a partir dessa disciplina de suma importância para agregação de valor, competitividade e produtividade às ações comerciais que impulsionam o crescimento econômico da sociedade.

O experimento foi dividido em dois momentos: o momento inicial foi no primeiro bimestre, que compreendeu o período de julho de 2019 até setembro de 2019 e o segundo momento no bimestre subsequente que compreendeu o período de outubro de 2019 a dezembro de 2019. É importante ressaltar que é extremamente conveniente que as avaliações dessa disciplina sejam práticas, em computador, e que os resultados sejam os desejados na situação-problema proposta na avaliação, pois sintetiza uma possibilidade do mundo real.

No primeiro momento, as aulas foram ministradas de forma tradicional, conforme planejamento padrão, ou seja, em cada aula um novo assunto e avançando de forma progressiva. Durante as aulas foram expostos os conceitos em Slides e os exemplos práticos apresentados no computador sendo projetado em tela grande para apreciação dos estudantes que, após as explicações, faziam os exercícios propostos no laboratório do Estabelecimento de Ensino.

No segundo momento, todos os conteúdos do primeiro bimestre foram produzidos em vídeo, disponibilizados aos estudantes e as novas aulas foram ministradas diretamente no computador, utilizando situações-problema demandantes da utilização de banco de dados (que é a disciplina contemplada nesse relato), porém com o computador equipado com o software Camtasia Studio, de propriedade da empresa TechSmith Corporation e um microfone de lapela plugado no computador e preso ao professor. O Camtasia foi configurado para capturar a tela do professor, bem como seu áudio cujo conteúdo eram as explicações das situações demonstradas. Após a aula, os vídeos eram produzidos e o upload para um canal do professor no YouTube era realizado e, em seguida, disponibilizado na plataforma Google Sala de Aula (Classroom) junto com novos exercícios com maior carga de quantidade e complexidade nas inserções, edições, exclusões e principalmente 
nas consultas à base de dados de cada exercício. Vale ressaltar que a cada aula os conteúdos foram avançando de forma progressiva, tal como no primeiro momento.

\section{ANÁLISE E DISCUSSÃO DOS RESULTADOS}

No primeiro momento da experiência, os estudantes apresentavam dificuldades em avançar em novo conteúdo, pois o anterior não estava totalmente fixado devido à baixa memorização dos novos comandos SQL. As dificuldades aumentavam na medida em que o bimestre avançava e também os novos conteúdos eram ministrados. Ao final do bimestre, somente dois alunos conseguiram nota satisfatória, sendo uma nota 6,5 e outra 6,0 . 0 somatório de pontos da turma foi de 43,25 e a média por aluno foi de 3,1 , sendo o total de 14 estudantes em sala.

No segundo momento da experiência, os estudantes a cada semana estavam mais seguros de si e mais engajados com as situações e problemas propostos. Foi relatado pelo professor que, durante o período, pelo menos metade da turma fez perguntas avançadas sobre o conteúdo e $72 \%$ da turma se mostraram participativos na plataforma Google Sala de Aula (Gráfico 1). Os vídeos puderam ser acessados fora do espaço formal de ensino, em qualquer dia e horário, podendo ser visto e revisto quantas vezes o estudante quisesse.

Gráfico 1 - Análise do percentual de alunos

\section{Percentual de alunos que melhoraram o desempenho em comparação ao 1a Bimestre}

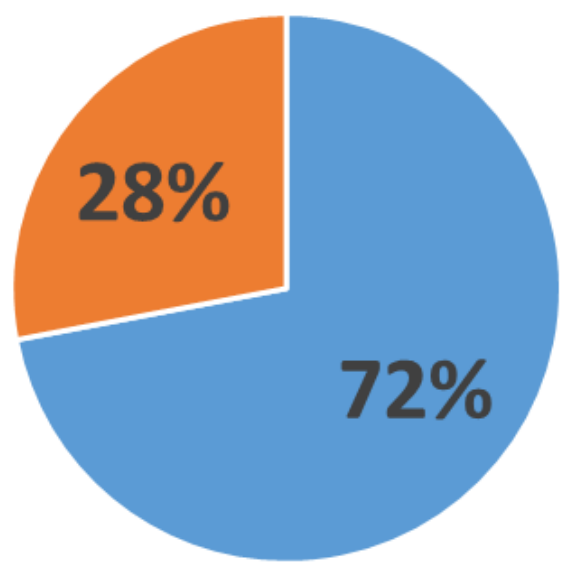

- Melhor desempenho " Sem variação

Fonte: Elaborado pelos autores (2020).

Assim, as atividades propostas sempre eram realizadas com bom nível de qualidade e assertividade o que levou a melhores resultados na avaliação: i) somatório de notas: 82,0; ii) média da turma: 5,8; iii) Somente cinco dos 14 estudantes tiraram nota abaixo da média $(6,0)$ estipulada pela escola; iv) de todos os que tiraram nota abaixo da média no primeiro bimestre (momento inicial da pesquisa), $72 \%$ tiveram desempenho melhor que no primeiro momento da pesquisa, sendo que $58 \%$ se recuperaram de forma a serem aprovados sem necessidade de prova final; $v$ ) dos cinco estudantes que foram para a prova final, $100 \%$ não acessaram a plataforma e conteúdos, ou acessaram em quantidade de tempo irrelevante para uma aprendizagem significativa; vi) Desses cinco estudantes que foram para a prova 
final, apenas um teve melhoria no desempenho no segundo momento da pesquisa, tendo dobrado sua nota, porém insuficiente para progredir sem prova final, tendo os outros quatro estudantes desempenho ligeiramente inferior que no primeiro momento.

É possível concluir que o vídeo tem grande potencial para aprendizagem significativa e sólida no ensino técnico em informática. Os estudantes se sentem motivados e valorizados à medida que conseguem progredir e elevar seu nível de qualidade em relação ao ponto inicial e, consequentemente, se sentem mais seguros para as resoluções práticas do mundo real inerentes à área de atuação. Dessa forma, é possível vislumbrar a exploração do potencial metodológico apresentado utilizando ferramentas disponíveis no mercado, aplicando em outros cursos técnicos, a fim de qualificar os futuros profissionais para as demandas atuais do mercado de trabalho e preparação dessa mão de obra para um futuro próximo em que serão necessárias habilidades tecnológicas para a inovadora indústria 4.0.

É importante ressaltar que existe uma parcela da turma (28\% ou quatro estudantes em números absolutos, de um total de 14) que teve desempenho aquém em relação ao primeiro momento da pesquisa. Esses casos devem ser estudados posteriormente para melhor observação dos motivos pelos quais houve uma piora em seus resultados e fatores como acesso à Internet, motivos pessoais, dificuldade com o conteúdo em vídeo, distúrbios de aprendizagem ou outros fatores que possam ter interferido em sua performance.

\section{CONSIDERAÇÕES FINAIS}

O crescente avanço tecnológico se constitui em empreendimentos com fins econômicos que envolvem os diversos segmentos sociais e a escola acaba sendo levada a fazer parte do processo, cabendo aos professores, pesquisadores fazerem da tecnologia um instrumento didático, que pode ser apresentado como recursos e materiais de apoio ao ensino e à aprendizagem.

A utilização de vídeo em sala de aula é uma estratégia didática que pode ser vista como um agente de mudanças para a melhoria da qualidade do ensino; especificamente neste trabalho, o ensino voltado para a área de informática. Mas tal prática requer professores preparados para a utilização de mídias e objetos digitais como materiais didático-pedagógicos, sendo necessária a aquisição de conhecimentos da didática e dos conteúdos, para a contribuição do desenvolvimento de práticas pedagógicas que utilizem as multimídias como interfaces que atendam às necessidades individuais e coletivas, assim, o docente certamente poderá contribuir para o estímulo de uma construção criativa do conhecimento, bem como da capacidade de reflexão do discente por meio de um ambiente de ensino interativo.

De acordo com os resultados desta pesquisa, pode-se notar que os alunos que fizeram uso da plataforma digital conseguiram melhor performance na disciplina, pois a partir do momento que foi ofertado um conteúdo da disciplina em forma digital e o mesmo pôde ser acessado a qualquer momento e em qualquer lugar, possibilitou que o aluno pudesse rever e reforçar o conteúdo estudado. Além disso, a gravação das aulas de forma automática e disponibilizada no YouTube, são ferramentas facilitadoras para que o aluno possa também rever o conteúdo repassado pelo professor como se estivesse vivenciado novamente aquela aula presencial.

Como apresentado nesta pesquisa, os alunos que tiveram um rendimento abaixo da média no primeiro bimestre, no segundo, puderam reverter este cenário através do uso 
destes recursos digitais de modo que a maioria fosse aprovada sem prova final, isso mostra de forma nítida a importância do estudo complementar fora da sala de aula.

Com a revolução digital atravessando empresas privadas e públicas e órgãos públicos, cabe a escola a pesquisa e o uso destes recursos digitais como fomento desta complementação dos estudos para que o aluno veja que a escola está fazendo parte de todo esse contexto social. Ações por parte do professor são importantes, mas a escola como um todo precisa compactuar com esta ideia.

Google Sala de Aula, gravação automática e YouTube fazem parte de um número bem pequeno de recursos digitais comparado a tudo que existe e possa ser usado como auxiliador e fomentador de processo de ensino-aprendizagem, mas que nesta pesquisa foram as ferramentas utilizadas de maneira contextualizada pelo professor objetivando motivar e melhorar o índice de desempenho.

Isto mostra a importância do professor como um agente de transformação neste processo de ensino-aprendizagem, dando ao aluno ferramentas para um melhor desempenho e sucesso no mercado de trabalho e também ajudando a dar mais autonomia ao aluno para que ele busque de forma mais amplificada dar asas à sua criatividade e tomada de decisão que são elementos cognitivos importantes no mundo atual cercado de tecnologia digital.

\section{REFERÊNCIAS}

ASSIS, R. L. M. de; ROSADO, I. V. M. A unidade teoria-prática e o papel da supervisão de estágio nessa construção. Rev. katálysis, Florianópolis, v. 15, n. 2, p. 203-

211, Dec. 2012. Disponível em:

http://www.scielo.br/scielo.php?script=sci_arttext\&pid=S1414-

49802012000200006\&lng=en\&nrm=iso. Acesso em: 10 fev. 2020.

CARVALHO, C. de S. Importância da inserção de filmes e vídeos na prática docente no ensino fundamental. 2017. Disponível em:

http://www.ufjf.br/pedagogia/files/2017/12/Import\%C3\%A2ncia-da-

Inser\%C3\%A7\%C3\%A3o-de-filmes-e-v\%C3\%ADdeos-na-pr\%C3\%A1 tica-docente-noEnsino-Findamental-I.pdf. Acesso em: 10 fev. 2020.

DALLACOSTA, A. et al. O vídeo digital e a educação. Workshop em Informática na Educação. UFAM, 2004.

FIRJAN; SENAI; FINEP. Indústria 4.0 no Brasil: oportunidades, perspectivas e desafios. Brasil, 2019.Disponível em: https://www.firjan.com.br/publicacoes/publicacoes-deinovacao/industria-4-0-no-brasil-oportunidades-perspectivas-e-desafios.htm. Acesso em: 8 fev. 2020.

IBGE. Pesquisa Nacional por Amostra de Domicílios Contínua: Medidas de Subutilização da Força de Trabalho no Brasil. Divulgação Especial. Brasil, 2019.

LUNETAS. Videoaula e 'edutubers': como o youtube mudou o jeito de estudar? Disponível em: https://lunetas.com.br/videoaula-educacao-youtube. Acesso em 8 fev. 2020

MATOS, J. de S. A Indústria 4.0 na economia brasileira: seus benefícios, impactos e desafios, 2018. 42 f. Monografia (Graduação). Universidade Federal de Uberlândia.

Disponível em:

https://repositorio.ufu.br/bitstream/123456789/23894/1/Ind\%C3\%BAstriaEcnomiaBrasileira .pdf. Acesso em: 20 fev. 2020. 
SANTOS, C. M. dos. Na prática a teoria é outra? Mitos e dilemas na relação entre teoria, prática, instrumentos e técnicas no Serviço Social. Rio de Janeiro: Lumen Juris, 2010.

SANTOS, V. G. dos; ALMEIDA, S. E. de; ZANOTELLO, M. A sala de aula como um ambiente equipado tecnologicamente: reflexões sobre formação docente, ensino $e$ aprendizagem nas séries iniciais da educação básica. Revista Brasileira de Estudos Pedagógicos. Brasília, v. 99, n. 252, p. 331-349, Mai./Ago. 2018. Disponível em: $<$ http://www.scielo.br/scielo.php?script=sci_arttext\&pid=S217666812018000200331\&lng=en\&nrm=iso>. Acesso em: $21 \mathrm{fev} .2020$.

SERAFIM, M. L.; SOUSA, R. P. de. Multimídia na educação: o vídeo digital integrado ao contexto escolar. [online]. Campina Grande: EDUEPB, 2011. Disponível em:

http://books.scielo.org/id/6pdyn/pdf/sousa-9788578791247-02.pdf. Acesso em: 20 fev. 2020.

VIEIRA, K. V. M., SOUSA, R. P. Objeto de aprendizagem empregado como recurso multimídia na microbiologia. In: SOUSA, R. P., et al., orgs. Teorias e práticas em tecnologias educacionais [online]. Campina Grande: EDUEPB, 2016. Disponível em: http://books.scielo.org/id/fp86k/pdf/sousa-9788578793265-06.pdf. Acesso em: 05 fev. 2020. 